\title{
A case study for the Ecovillage at Currumbin - integrated water management planning, design and construction
}

\author{
C. J. Tanner \\ Bligh Tanner Pty Ltd, Australia
}

\begin{abstract}
This paper will present a case study of the planning and development of the multi-award winning the Ecovillage at Currumbin, Queensland. The paper will focus on the integrated water management systems that have been implemented at the Ecovillage. The case study will present the vision, objectives and implementation of the Ecovillage including tracing the vision and objectives through the life of the development, comparing the outcomes to the objectives. The Ecovillage is a new type of development in which the objectives address the triple bottom line - economic, social and environmental - and result in new forms of development, for example reversing the usual ratio of private land: community land.
\end{abstract}

The integrated water management systems are described briefly as follows.

- There are no connections of either water or wastewater to municipal supplies, and it is understood that this is the first residential development in Australia to achieve this.

- All rainwater falling on house roofs is collected in rain tanks and used to supply all potable water needs to the householder.

- All site stormwater is managed by a system of swales, bio retention filters and ponds so that the development does not change either the water quality or water quantities of site runoff from pre to post development. Site stormwater collected in ponds is available for re-use to agricultural areas of the development.

- All wastewater is collected via a low infiltration sewer reticulation system, treated to Class $\mathrm{A}+$ and recycled for site irrigation, household toilet flushing and household external uses eg car washing.

The lessons learned are wide ranging and include the need to develop a strong process based delivery from concepts through to construction, the need for systems thinking in design, with complex analysis supporting detailed design, and innovative construction management to achieve a world's best practice development.

Keywords: subdivision, planning processes, water sensitive urban design, integrated water management. 


\section{Introduction}

Located on Currumbin Creek in the Gold Coast of Queensland, the Ecovillage at Currumbin is a sustainable development in the fastest growing region of the OECD in the world's most urban nation, which is also the driest inhabited continent. The Ecovillage is a 144-lot subdivision with no mains connections to water or wastewater. The developer, Landmatters, aims to adopt world's best practice and to create the world's best Ecovillage. Sustainability objectives direct all aspects of the development. The site is self-sufficient for water supply and all wastewater will be beneficially recycled. The site has achieved a $20 \%$ residential: $80 \%$ community open space ratio - the reverse of most conventional developments. Dwellings are clustered around community greenways; substantial areas are set aside for food crops, recreational open space and conservation areas. Recycled building materials have been used wherever possible. An on-site recycling centre will be provided. A resource management system, Ecovision ${ }^{\circledR}$, monitors and manages resource use [1].

In Australia it is clear that a more sustainable approach to the management of urban water resources is needed: the pressure of growing population, limited new water sources and climate variation all demand change. Nowhere are these factors more keenly felt than in South-East Queensland. The purpose of this paper is therefore not to discuss the need to promote sustainable integrated water management design in urban development, but rather to report on a unique project in the region that is substantially completed and demonstrates what can be achieved. The Ecovillage at Currumbin recently won the Queensland Environmental Protection Agency Award for Most Sustainable Development 2006 and the Urban Development Institute of Australia's (Queensland) Best Sustainable Development and Best Small Subdivision in 2006. This project is significant for several reasons: rainwater is used as the primary source of drinking water supply; wastewater recycling provides water for residential toilet flushing and garden watering; water sensitive stormwater design is incorporated; and it demonstrates what can be achieved where community title allows for common ownership and mutual responsibility [1].

Bligh Tanner is the principal consultant for the Ecovillage and has been instrumental in the development and delivery of the water management systems. The significant contribution of other consultants is also acknowledged, in particular Andrew King (EECO) and WBM Oceanics (part of the BMT Group).

\section{Objectives and the planning process}

A rigorous approach to the planning and design process was adopted. The first step was the definition of a vision and objectives specific to the development. The vision adopted was 'To create the world's best Ecovillage' [2]. To support the vision, the developer and consultant team brainstormed objectives called Desired Environmental Outcomes (DEOs) [3]. Furthermore, the DEO's reflect a number of the objectives of the local shire planning scheme, some of which are listed below: 
The local Shire Council town plan required, among other things, the following:

- $\quad$ to minimise disturbance to natural landscape and wildlife habitats;

- $\quad$ to protect areas of nature conservation, buffers, separation of areas and continuity of open space should be established around these regions;

- to minimise disturbance to surface drainage, water courses, tidal and ground water movement;

- $\quad$ to conserve land and soil resources;

- $\quad$ to protect marine and freshwater habitats and water quality;

- $\quad$ to link areas of habitat and provide corridors for wildlife movement.

The DEO's relate to the requirements outlined above, and specific objectives of the Developer. They encompass both local and global considerations and are expected to be sustained over the full life of the development.

\subsection{Ecological objectives}

Ecol. 1 Restore, maintain and enhance biodiversity through the protection and enhancement of existing significant habitat;

Ecol. 2 Minimise initial and continuing consumption of resources and energy through the application of energy efficient design principles; the reduction of private motor vehicle usage; optimizing local food and production opportunities; and the reuse and recycling of water, wastes and other materials;

Ecol. 3 Minimise impact and change to air, soil and water, thereby ensuring equity for all elements of the natural environment whether living or inanimate;

Ecol. 4 Promote awareness and understanding of sustainability, including ecological issues and reduced energy consumption. and reduced materials consumption;

Ecol.5 Minimise impact on global environment by optimising local ecological food and material production opportunities.

\subsection{Social objectives}

Soc. 1 Respect and honour Indigenous and other cultural, historical and spiritual values of the land and its surrounds;

Soc. 2 Enable social equity and diversity, honouring differences and catering for the needs of individuals through the different stages of life;

Soc. 3 Maximise health, safety and comfort in the built environment to provide enduring quality of life;

Soc. 4 Foster and promote social cohesion within the village community and a deep sense of human connection to and interdependence with the land;

Soc. 5 Utilise aesthetic sensitivity to create a continuing sense of place and beauty; 
Soc. 6 Facilitate integration of the village with the broader local community through the shared achievement of common objectives and the promotion of openness within the village.

\subsection{Economic objectives}

Econ. 1 Promote initial and ongoing ecovillage economic viability through excellence of design;

Econ. 2 Minimise operational and maintenance costs;

Econ. 3 Minimise obsolescence through enduring component life cycle design;

Econ. 4 Provide for change and re-use at minimal cost / loss;

Econ. 5 Enable economic productivity and ecological contribution to local and world systems and economies.

In keeping with the DEOs, in particular Social Objectives 1 and 6, the developers chose to advertise their intention to develop the land before any plans or fixed ideas had been determined. The land is located in a sensitive environment in which lives a close and generally conservative community. Notifying the community of the developers' intentions was courageous because it gave the public far greater opportunity to influence the local authority and other community members against the development. The developer hosted a community meeting at which the vision and DEOs were explained, and a weeklong public consultation was held. The open consultative approach succeeded extremely well, with most community input aimed at positively influencing the outcomes. Community members were comforted by the vision and DEOs because they understood how these would help protect the environment in which they lived. In addition, many members of the public were interested in the water cycle, in understanding the innovative approaches which were being discussed and in public health issues. For example, there was widespread support for UV disinfection rather than chlorination of water because it was recognised as a healthier outcome that was also better for the environment.

Finally, the objectives have been significant in the management of the entire development, not only the planning process because the DEOs underpinned the strong direction of the development processes. At all stages of the design process, ie concepts through to construction specifications, the DEOs have been used to guide the overall outcomes. For example, consider how the use of rainwater tanks relates to the three DEOs below (one from each category: Ecol 3, Soc 3 and Econ 2):

- minimise impact and change to air, soil and water, thereby ensuring equity for all elements of the natural environment whether living or inanimate;

- maximise health, safety and comfort in the built environment to provide enduring quality of life;

- $\quad$ minimise obsolescence through enduring component life cycle design; The use of rainwater tanks with appropriate treatment satisfies all three of these objectives in these ways: 
- reducing the directly connected impervious area, which benefits stream flow;

- reducing the amount of runoff needing to be treated to manage the water quality impacts of urbanisation;

- $\quad$ by using with appropriate filtration and disinfection rain water provides a safe and healthy water source for the users;

- a rainwater tank has a relatively high capital cost, (although not much more than the costs of providing trunk water supplies to lots) but maintenance costs are low, and replacement life cycles are long, so life cycle costs are comparable to alternatives.

\section{Design outcomes - IWM initiatives}

\subsection{Integrated water management systems description}

This section describes the integrated water management systems. The Ecovillage has no municipal water or wastewater connections - probably the first residential development in Australia to achieve this. The decision not to have these connections has significantly influenced the site water management strategies.

- All site stormwater is managed by a system of swales, bio retention filters and ponds so that the development does not change either the water quality or water quantities of site runoff from pre to post development. Site stormwater is collected in ponds from where it is available for re-use on agricultural areas of the development. Coupled with natural vegetation, the ponds provide a highly aesthetic environment for a residential development.

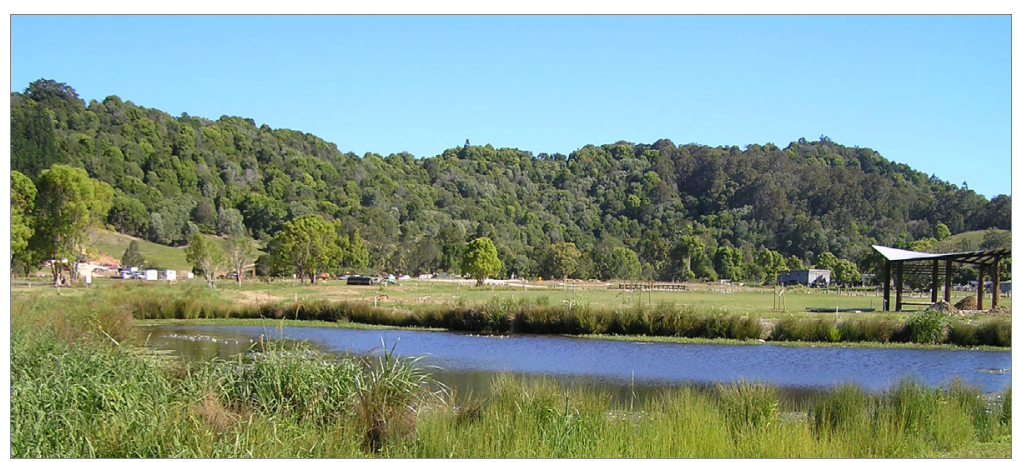

Figure 1: Stormwater pond.

- All rainwater falling on house roofs is collected in rain tanks and used to supply all potable water needs to the householder. Each domestic tank will also provide a $5 \mathrm{~kL}$ fire-fighting volume and a stormflow attenuation zone. The water will be filtered and UV disinfected prior to use. A range of tank 
sizes has been determined based on house bedroom numbers: approximately $20 \mathrm{~kL}$ for a 1-bedroom house to $40 \mathrm{~kL}$ for a 3-bedroom house. These tanks will provide $99 \%$ of potable water requirements. If the tank runs low then the householder will need to purchase water by tanker. Householders will be encouraged to use water wisely and a comprehensive range of water efficient devices will be required in each house. Ecovision ${ }^{\circledR}$ will provide quick access to household water consumption data and allow the Body Corporate to restrict supply to individual gardens if use is exceeds parameters set by the Body Corporate.

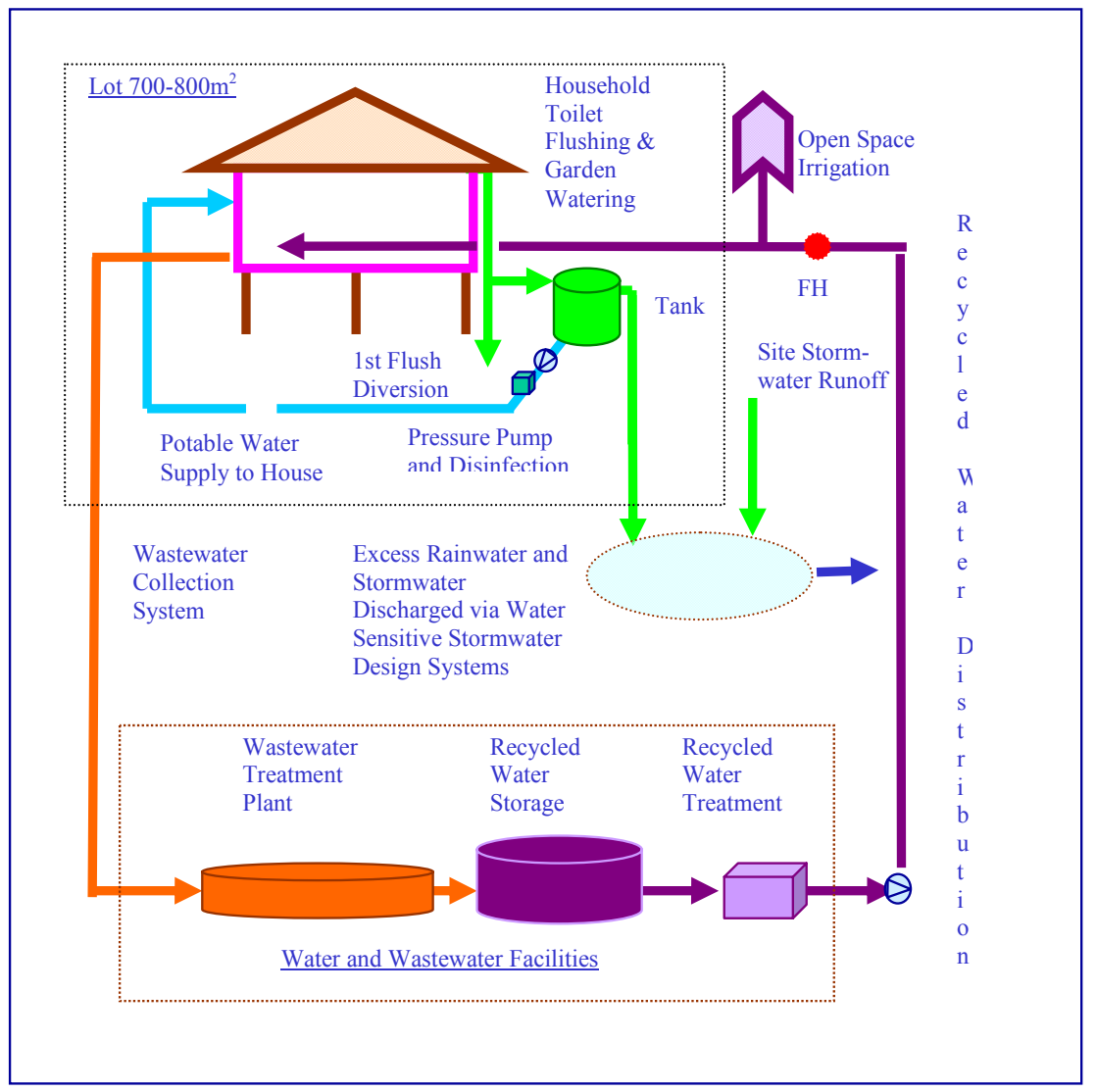

Figure 2: $\quad$ Integrated water management schematic.

- All wastewater is collected via a low infiltration sewer reticulation system (heat welded PE pipes; 'Poo Pit' access chambers instead of manholes), treated to Class $\mathrm{A}+$ and re-cycled for site irrigation, household toilet flushing and household external uses such as car washing. Secondary wastewater treatment is provided in an Orenco Advantex ${ }^{\circledR}$ textile filter 
system incorporating primary pre-treatment and an anoxic zone for denitrification. Final polishing is provided by Memcor micro-filtration, UV disinfection and residual chlorination. There will be no direct discharge of recycled water from the site. The design allows for $98 \%$ beneficial reuse with the balance dispersed by over-irrigation on the site. The water and wastewater system is illustrated below.

\subsection{Significance of the IWM systems used}

The integration of the water systems is a key innovation. Traditionally these systems have been designed and constructed as separate systems, with stormwater and wastewater treated as disposal items and water to be sourced externally from independent systems. This approach fails to recognise the potential of each of these water systems as a resource. An IWM system is more complex to understand and model during the design process than the traditional model. It requires experienced engineering and environmental input in terms of systems and detail design.

The stormwater conveyance systems were all modelled in XP-SWMM. This model provides for hydrological routing based on synthetic or historically recorded rainfall patterns, through complex urban systems incorporating houses, rain tank systems, swale and piped drainage, bio retention filters, wetlands and the like. It also has the capability to model water quality (although that was not used in this case). The stormwater model must properly account for detention and retention in the system, because the accumulation of many small storages, in rain tanks, swales and bio retention filters is significant.

The MUSIC model was used to design the water quality management systems. This model simulates rainfalls and pollutant decay using exponential decay rate equations empirically calibrated to match experimentally measured results. The model tallies daily rainfall and evaporation, determines runoff and routes this through the water quality devices.

The MEDLI model was used to simulate the mass balance of water and nutrients for irrigation of land using recycled water. This also provided an estimation of likely frequency of discharge to the environment and the water quality of the discharge, which was then used in the MUSIC model.

Bligh Tanner developed an Excel spreadsheet to undertake a water balance for households using rain tank systems and for the overall site water balance.

During the concept design stage Multi Criteria Analysis, including life cycle cost components, was undertaken to review options in the systems against the DEOs.

\subsection{The costs of IWM}

The up front costs of water infrastructure are generally greater at the Ecovillage than for more traditional subdivision. However, these costs do not consider any of the benefits that the self-sustaining, environmentally sensitive systems of the Ecovillage provide. Nor do they take into account an environmental cost of the traditional systems. In the Pimpama Coomera Strategic Stormwater Study [4] a 
rigorous assessment of Business as Usual (BAU) costs compared to an integrated water management (IWM) approach found that the IWM costs were only marginally higher than BAU on a life cycle basis.

The water management system adopted for the Ecovillage has wide ranging benefits. It is self-sufficient, it provides the Ecovillage Community with water for agricultural uses, it provides aesthetic benefits, and it provides all the drinking water for the community. The environmental impact is considered to be low, and nutrients consumed by the community will be recycled to grow food for the same community.

\section{Contracting and construction innovations}

Infrastructure for the Ecovillage is two-thirds completed. Several major construction contracts have been let and completed during this process. Satisfying the Vision and DEOs, while maintaining quality and cost control of contracts and providing sufficient flexibility to accommodate site led modifications to works has required an alternative approach to standard construction contracts. The key innovations in this regard have been:

- Short-listing suitable contractors (to 2 or 3) by an extensive review facilitated by a comprehensive Expression of Interest process;

- Preliminary tender pricing by short listed contractors to select a preferred contractor;

- Negotiated contracts with the preferred contractor;

The negotiations with the preferred contractor have been extensive including reviews of:

- All works required detailed discussions of proposed work method statements, including consideration of alternatives, sometimes at greater monetary cost, but lower environmental impact;

- All material supplies, again including consideration of alternatives;

- Environmental and administrative management systems;

- Contractors Site personnel with a focus on the key site people being personable and flexible, and obviously competent at their work;

- Pricing of any unusual job scope items;

These negotiations have been completed prior to signing contracts and commencing work. However, at the time the preferred contractor is selected, a strong commitment has been made to them, so that they have felt comfortable proceeding with the time consuming, hence costly negotiations.

Key outcomes from this process have been:

- High site attendance by the owners, or senior management of the construction companies to allow quick decisions on matters of costs, timing, resources and alternative work methods. This has been specifically required and separately costed in the construction contracts;

- Introduction of a system of hold points to allow the developer and consulting team input to the procurement of materials, and work methods for the construction phase. This has enabled wide-ranging discussion of 
alternative designs not necessarily considered during the design process, or of construction methods and materials to obtain better environmental outcomes.

An example of this is the construction of gravity sewer reticulation. The design (and local authority guidelines) generally called for sewers to be constructed at a $1 \mathrm{~m}$ offset from allotment boundaries. This location often fell on land with relatively steep side slopes. Preliminary work method statements for the construction had been submitted, reviewed and approved by the developer. This was reviewed on site and alternatives were determined to shift the sewer off the side slopes, often up to $10 \mathrm{~m}$ clear of the allotment boundaries, and to use low grade geo-fabrics over existing grass cover to protect it during machine operations. Shifting off the side slopes reduced the volume and surface disturbance of earthworks and the geo-fabrics protected the underlying grasses and demarcated an area in which the construction vehicles were to work. Protecting grasses reduced the potential for erosion and sediment transport to the creek to almost nil.

\section{Conclusions}

The conclusions are wide ranging and include the following points.

- A strong process is essential to maintain the direction and integrity of an ecovillage development, in particular when complex inter-related issues arise;

- Using an integrated water management system it is possible to develop a community that has a very low impact on the environment, on local and regional sources of water, and on local waterways. To achieve this designers must be systems thinkers and capable of detailed design using complex analysis;

- A flexible approach to construction contracts is required, recognising the costs and benefits to both parties (Contractor and Developer) of a collaborative approach;

\section{References}

[1] Hamlyn-Harris: Bligh Tanner Pty Ltd;

[2] Landmatters Pty Ltd;

[3] Landmatters Pty Ltd, Bligh Tanner Pty Ltd, John Mongard Landscape Architects Pty Ltd, Andrew Hall Town Planning Pty Ltd, WBM Oceanics Pty Ltd;

[4] Gold Coast City Council 